\title{
31.2. INTERSTITIAL WATER CHEMISTRY: DEEP SEA DRILLING PROJECT, LEG 13
}

\author{
B. J. Presley, ${ }^{1}$ Chari Petrowski, and I. R. Kaplan, Department of Geology and Institute of Geophysics and Planetary Physics, \\ University of California, Los Angeles, California
}

\section{INTRODUCTION AND PROCEDURES}

Drilling during Leg 13 of the Deep Sea Drilling Project was confined almost exclusively to the Mediterranean Sea. This was the first time deep drilling had been conducted in a so-called small, or inland, ocean basin, and the sediments penetrated turned out to be extremely complex, both lithologically and stratigraphically. There was abundant evidence of erosional loss of sediment at some locations and equally clear indications of large scale faulting, bringing old rocks up over younger sediments. Almost every possible sediment and rock type was involved in this tectonic activity. For example, pelagic oozes, sapropels, evaporites, pebble conglomerates, detrital gypsum, nodular anhydrite, and sand layers were described in the cores which were squeezed for pore water. These were of ten interlayered and otherwise showed evidence of varying environmental conditions with time.

The interstitial water chemistry is, as would be expected, highly variable, both with depth and location. The mechanisms which lead to variability in interstitial water chemistry are poorly understood, even in areas of uniform lithology (see previous leg reports). Here lithologic changes and tectonic activity complicate the picture, making interpretation very difficult.

A total of eighteen samples, which had been collected at five drilling sites, were received at U.C.L.A. These had been forced through a 0.45 micron filter immediately after removal from the sediment and had been stored at $4^{\circ} \mathrm{C}$ in sealed plastic syringes. Analysis was started as soon as the samples were received, nevertheless this was as long as three months after collection.

The analytical procedures currently being used in our pore water program are essentially those described in some detail elsewhere (Presley, 1971; Presley and Claypool, 1971). These procedures have evolved as we have sought to get more and better data from the small samples provided by the Deep Sea Drilling Program. Therefore, the procedures used for Leg 13 may, in some instances, be modifications of those described in the references, but any changes are considered not sufficiently significant to warrant a separate description here.

\section{RESULTS AND DISCUSSION}

All data that we have obtained to date from the water samples is given in Table 1, except major cation concentrations which were omitted, as they are discussed in the report by Sayles et al. (this volume). The shipboard $\Sigma \mathrm{CO}_{2}$ values which were given in our previous reports have been omitted here, because, as on previous legs, the laboratory and shipboard values show moderately good agreement, and the laboratory values are more reliable.

\footnotetext{
${ }^{1}$ Present address: Department of Oceanography, Texas A\&M University, College Station, Texas.
}

Chloride and bromide values have been close to those of average seawater in samples from previous legs, except in locations where the presence of evaporites was known or implied, and in a few locations that apparently were influenced by continental ground water. The Leg 13 samples show a sharp increase in both components with depth, and once again the change is clearly due to the presence of evaporite minerals. Gypsum and anhydrite were identified in the deepest sample analyzed at Site 125, and were reported about 60 meters below the deepest sample we obtained from Site 124. Chloride concentration at Site 124 was more than twice that at Site 125 , however, and the $\mathrm{Cl} / \mathrm{Br}$ ratio was much more abnormal there (507 compared to 306 , when seawater gives 290 ). This can only be due to a difference in the history of the two evaporite sequences, one of which is in the Balearic Basin (124) and the other in the Ionian Basin (125).

Site 127 was also drilled in the Ionian Basin, and the interstitial water there was even more enriched in $\mathrm{Cl}$ than at Site 124, despite the fact that only Quaternary sediments were sampled. Here too the $\mathrm{Br} / \mathrm{Cl}$ ratio is highly abnormal, but in an opposite sense to that at Site 124. That is, here $\mathrm{Br}$ is enriched relative to $\mathrm{Cl}$, as would be expected in a very late stage evaporite deposit or a residual liquor. The bottom sample from Site 124, on the other hand, must have resulted from the leaching of relatively pure $\mathrm{NaCl}$. The $\mathrm{Cl} / \mathrm{Br}$ ratio at Site 125 differs from the seawater value by only 5 percent and it seems likely that no halite is associated with the anhydrite recovered at this site.

Lithium concentrations up to thirteen times those of seawater were measured in Leg 13 pore waters, and while the enrichments seem to be related to salinity increases, they are not due solely to such increases. At Site 127 for example, the $\mathrm{Li} / \mathrm{Cl}$ ratio is near seawater value at 22 meters depth, considerably lower at the next two sampled depths $(43 \mathrm{~m}$ and $52 \mathrm{~m})$, and again near the seawater ratio at 108 meters and 233 meters. The ratio jumps sharply to more than three times that of seawater at 290 meters and the bottom sample at 336 meters has a ratio more than twice that of seawater. The $\mathrm{Li} / \mathrm{Cl}$ ratio at depth at other sampled sites is also two to three times that of seawater. Thus, some mechanism of $\mathrm{Li}$ release to the pore water has been operating, as it has on many of the sites sampled on previous legs.

Boron was depleted relative to chloride on all Leg 13 samples. The $\mathrm{B} / \mathrm{Cl}$ ratio varied from abour 1.5 to 4 times less than the seawater value, which is more of a variation than has been found on most previous legs. The one high salinity sample from the Gulf of Mexico (Leg 10) which we analyzed for B was depleted by a factor of 10 , however, so perhaps this is a common phenomenon.

Silicon too showed considerable variation in concentration in these samples, but this would be expected with such diverse lithologies. There is little relationship between 


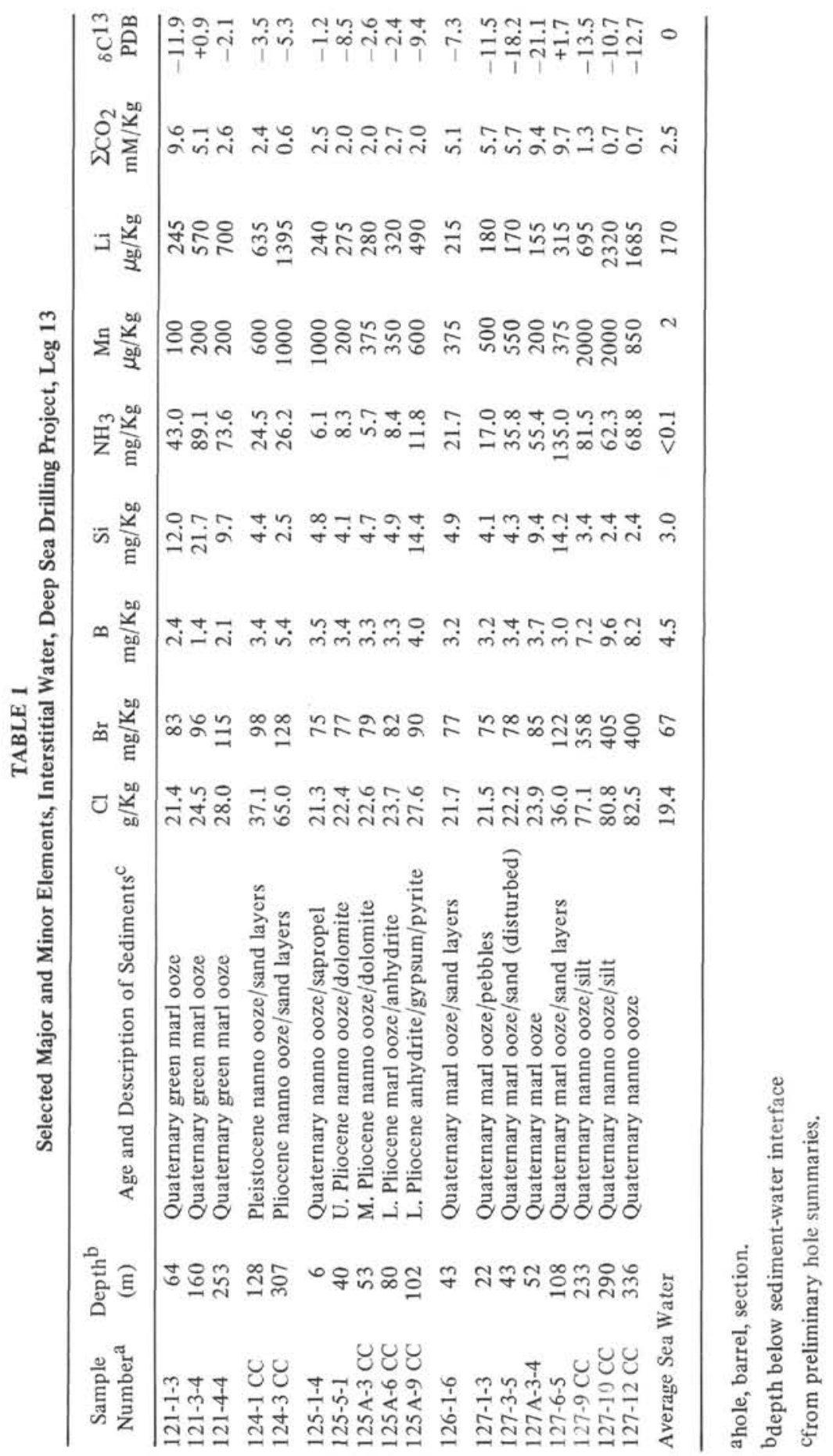

the salinity and the $\mathrm{Si}$ concentration, except that the four highly saline samples $(\mathrm{Cl}<65 \%$ ) all had low $\mathrm{Si}$ content.

Ammonia was highly enriched in all Leg 13 samples, as has been the case with biogeneous sediments on previous legs. Once again the dissolved ammonia concentration is much higher than would be predicted from the dissolved $\mathrm{CO}_{2}$ concentration, and increasingly so at greater depth. This is most likely the result of a loss of $\mathrm{CO}_{2}$ by carbonate precipitation, rather than an anomaly in the $\mathrm{C} / \mathrm{N}$ ratio released by organic matter.
The concentration of total dissolved carbonate species is higher than is typical for seawater at shallow depths, except for Site 125 , but decreases sharply with depth. The carbon isotope ratios show the source of the added $\mathrm{CO}_{2}$ to be organic matter (Presley and Kaplan, 1968), and the decrease in concentration is most likely due to carbonate precipitation.

Manganese concentrations show the wide variation that has characterized all of our pore water work, DSDP and otherwise. As usual there is no correlation between $\mathrm{Mn}$ and other measured parameters. 


\section{ACKNOWLEDGMENTS}

This work was supported in part by AEC Grant AT (11-1)-34 P.A. 134 and NSF Grant GA-20715.

\section{REFERENCES}

Presley, B.J. and Kaplan, I.R. 1968. Changes in Dissolved Sulfate, Calcium and Carbonate from Interstitial Water of Nearshore Sediments. Geochim. Cosmochim. Acta. 32, 1037.

Presley, B.J., 1971. Techniques for Analyzing Interstitial Water Samples. Part I: Determination of Selected Minor
31.2. INTERSTITIAL WATER CHEMISTRY

and Major Inorganic Constituents. In Tracey, J.I., Jr., Sutton, G.H. et al., 1971. Initial Reports of the Deep Sea Drilling Project, Volume VII. Washington (U.S. Government Printing Office). 1756.

Presley, B.J. and Claypool, G.E., 1971. Techniques for Analyzing Interstitial Water samples. Part II: Determination of total Dissolved Carbonate and Carbon Isotope Ratios, In Tracey, J.I., Jr., Sutton, G.H. et al., 1971. Initial Reports of the Deep Sea Drilling Project, Volume VII. Washington (U.S. Government Printing Office). 1749. 